\title{
Modeling and Simulation of Spatially Correlated Ground Motions at Multiple Onshore and Offshore sites
}

\author{
CHAO LI ${ }^{1,2}$, HONG HAO $^{2}$, HONGNAN LI $^{1},{\text { KAIMING } \mathrm{BI}^{2} \text { and BAOKUI CHEN }}^{1}$ \\ ${ }^{1}$ Faculty of Infrastructure Engineering, Dalian University of Technology, Dalian 116024, China \\ ${ }^{2}$ Centre for Infrastructure Monitoring and Protection, School of Civil and Mechanical Engineering, Curtin \\ University, Kent Street, Bentley WA 6102, Australia
}

A simulation method of spatially correlated seafloor motions is proposed by considering the influences of seawater on the seafloor motions and their spatial variations at different subsea sites. The offshore site transfer functions are theoretically derived using the fundamental hydrodynamics and one-dimensional wave propagation theory. Three-dimensional spatially varying ground motions on the surfaces of multiple onshore and offshore sites are synthesized based on the spectral representation method and the calculated site transfer functions. A pair of onshore and seafloor recordings from the same earthquake event is employed to examine the basic characteristics of simulated onshore and seafloor motions.

Keywords seafloor seismic motions; ground motion spatial variations; seawater layer; wave propagation theory; transfer functions

\section{Introduction}

In recent years, more and more offshore bridges, platforms and pipelines have been constructed to satisfy the increasing demand for transportation and offshore energy exploration of modern society. Many of these offshore structures are built in high seismicity regions. A key issue in the seismic design of such structures is the definition of input earthquake ground motions. Due to the insufficient data of seafloor earthquake recordings, onshore motions are commonly used as inputs in the seismic analyses of offshore engineering structures. This may lead to erroneous prediction of structural responses since the seismic motions on the seafloor may be very different from those on the onshore sites, owing to the fact that the presence of seawater layer can suppress the vertical seafloor motions near the $\mathrm{P}$-wave resonant frequencies of the seawater layer and indirectly affect the site amplification of ground motions by increasing the water saturation of subsea soil layers [Boore, 1997]. Moreover, during an earthquake, the seismic motions at different subsea supports of large span offshore structures are inevitably different due to the ground motion spatial variation effect [Hao, 1989], which can be primarily caused by the wave passage effect, the coherency loss effect and the local site effect [Der Kiureghian, 1996]. Both of the above mentioned two factors may significantly influence the seismic responses of large dimensional offshore engineering facilities. Therefore, it is necessary to realistically synthesize spatially varying seafloor motions for the seismic analyses of these large dimensional offshore structures.

The characteristics of seafloor seismic motions have been studied by some researchers

Address correspondence to Chao Li, Centre for Infrastructure Monitoring and Protection, School of Civil and Mechanical Engineering, Curtin University, Kent Street, Bentley WA 6102, Australia. E-mail: $\underline{\text { lichao17007@163.com }}$ 
during the last few decades. The seawater is normally regarded as an ideal fluid, which has no resistance to shear stress and therefore can only propagate P-waves. Crouse and Quilter [1991] developed a simplified model to calculate the ratio of vertical response of a site with a water layer above it to that without the water layer. They found that the seafloor vertical response can be significantly reduced near the resonant frequencies of P-waves in the water layer. More straightforward investigations were carried out by researchers through the statistical analyses of seafloor seismic data recorded by subsea earthquake stations, e.g., the Seafloor Earthquake Measurement System (SEMS) off the coast of Southern California, USA [Sleefe, 1990; Boore and Smith, 1999; Diao et al., 2014] and the strong-motion network (K-net) in Japan [Aoi et al., 2004; Okada et al., 2004; Chen et al., 2015]. It is revealed that the vertical component of seafloor motions are much lower than those of the onshore motions, especially at short periods, owing to the substantial reduction of the seafloor vertical motions near the $\mathrm{P}$-wave resonant frequencies of the overlying seawater layer. Moreover, the propagation of $\mathrm{P}$-wave in the subsea porous soil layers is also affected by the seawater since it can increase the degree of saturation and Poisson's ratio of the seafloor sediments. The two-phase media theory established by Biot [1956a, b] is the theoretical basis of the studies on the elastic wave propagation in fluid-saturated porous soils. Based on theory of Biot [1956a,b] and the homogeneous pore fluid concept [Verruijt, 1969], Yang and Sato [2000] proposed the formulas of P-wave velocity and Poisson's ratio for the porous soils and concluded that the vertical seismic motion could be significantly affected by the degree of saturation of soil layers. The research conducted by Wang and Hao [2002] also indicated that the water saturation level could remarkably impact the site amplification of the vertical component of seismic waves. However, although many studies have demonstrated that the seafloor seismic motions can be significantly influenced by the seawater, onshore motions are still commonly used as inputs in the seismic response analyses of offshore structures due to the scarcity of the seafloor earthquake recordings and the difficulty in considering the influence of seawater on the seafloor motions.

Ground motion spatial variation is another factor which greatly influences the structural seismic responses. The linear seismic response of large span structures can be directly calculated in the frequency domain by using the response spectra and ground motion spatial variation models as inputs at multiple structural supports [Bi et al., 2010]. However, for complex structures which usually behave nonlinearly during an earthquake action, the nonlinear response history analyses need to be carried out and the spatially varying ground motion time series are required to be simulated and used as inputs. Many stochastic simulation methods have been proposed to generate artificial spatially varying ground motions, among which the spectral representation method (SRM) is one of the most widely used methods. The representation concept of Gaussian random process was put forward by Rice [1944]. Shinozuka [1971, 1987] firstly employed this approach in the simulation of random processes. After that, many researchers extended this method to simulate spatially varying ground motions [Hao et al., 1989; Deodatis, 1996; Gao et al., 2012; Wu et al., 2014]. It should be noted that the influence of local site effect were rarely considered in these methods. Konakli and Der Kiureghian [2014] developed a simulation method of spatially varying ground motions including the differential site-response effect based on the site frequency response functions. $\mathrm{Bi}$ and Hao [2012] considered the local site effect by using the 
one-dimensional (1D) wave propagation theory [Wolf, 1985] and presented a simulation approach of spatially variable ground motions at uneven sites with varying conditions. This method directly relates local soil conditions with surface ground motions and is believed to yield more realistic simulation of spatially varying ground motions at a canyon site. However, the above methods are only suitable to simulate spatially varying ground motions on an onshore site. For the ground motions on an offshore site, the influence of seawater layer and soil saturation should be taken into account. The simulation technique of seafloor seismic motions cannot be found in the literature.

This paper proposes a simulation method of spatially varying ground motions on the surfaces of multiple onshore and seafloor sites. The offshore sites are assumed to be composed of the base rock, the multiple porous soil layers and an overlying seawater layer. The ground motion transfer functions of the layered subsea sites are theoretically derived by considering the effects of seawater layer and water saturation of subsea soil layers. The base rock motions are assumed to consist of out-of-plane SH-wave or in-plane combined P- and $\mathrm{SV}$-waves and propagate into the site with assumed incident angles. The spatially varying seismic motions on the free surface of base rock are modeled by the filtered Tajimi-Kanai power spectral density (PSD) function [Clough and Penzien, 1993] and an empirical coherency loss function [Sobczky, 1991]. The cross power spectral density matrix of ground motions at surface of various sites are calculated based on the derived offshore site transfer functions and the spatially correlated ground motions on the surfaces of multiple onshore and seafloor sites are synthesized using SRM. Moreover, a pair of recorded onshore and seafloor seismic motions are selected to examine the rationality and validity of the simulated motions by comparing the vertical-to-horizontal response spectral ratios of the recorded and simulated motions.

\section{Theoretical derivation of ground motion transfer functions for a rock site overlaid with a seawater layer}

For common fluids such as seawater, the viscosity coefficient is very low and can be neglected in most of the engineering hydrodynamics problems. Therefore, in this study, the seawater is regarded as an ideal fluid in which only seismic P-wave can propagate. Based on the fundamental hydrodynamics equations for an ideal fluid [Batchelor, 2000; Versteeg and Malalasekera, 2007] and the 1D wave propagation theory [Wolf, 1985], the ground motion transfer functions of an underwater rock site are theoretically derived, as briefed below.

\subsection{Hydrodynamics equations for seawater under earthquake excitation}

In hydrodynamics, the motion of an ideal fluid can be described with the conservation equation of mass, the Euler's equation and the adiabatic equation of state, which can be respectively expressed as [Versteeg and Malalasekera, 2007]

$$
\begin{gathered}
\frac{\partial \rho}{\partial t}+\nabla \cdot(\rho \boldsymbol{v})=0 \\
\frac{\partial \boldsymbol{v}}{\partial t}+(\boldsymbol{v} \cdot \nabla) \boldsymbol{v}+\frac{1}{\rho} \nabla P=0 \\
P=P(\rho)
\end{gathered}
$$

where $t$ represents time, $v$ denotes the fluid particle velocity, $\rho$ and $P$ are the fluid density and 
pressure. Essentially, earthquake wave is the transmission of the medium's perturbation around the equilibrium position. The fluid density and pressure can be written as $\rho=\rho_{0}+\rho^{\prime}$ and $P=P_{0}+p$, where $\rho_{0}, P_{0}$ and $\rho^{\prime}, p$ denote the static and perturbation of fluid density and pressure, respectively. It is obvious that the pressure perturbation is exactly the wave pressure induced by the earthquake excitation. Thus, the adiabatic equation of state, i.e. Eq. (3) can be expanded as:

$$
P=P_{0}+\rho^{\prime} \frac{d P}{d \rho}+\frac{1}{2}\left(\rho^{\prime}\right)^{2} \frac{d^{2} P}{d \rho^{2}}+\cdots
$$

For convenience, one can assume

$$
c_{p}^{2}=\frac{d P}{d \rho}=\left(V \frac{d P}{d V}\right)\left(\frac{1}{V} \frac{d V}{d \rho}\right)=\frac{K}{\rho}
$$

where $V$ denotes the fluid volume; $c_{p}$ is defined as the velocity of seismic $\mathrm{P}$-wave propagating in an ideal fluid and it is determined by the bulk modulus $K$ and density $\rho$ of the fluid.

Assuming the fluid medium is time-invariant, the parameters $\rho_{0}$ and $P_{0}$ can be taken as constants. Retaining the first order terms of Eqs. (1), (2) and (4), and eliminating the fluid pressure $p$, the linear wave equation of seismic P-wave in an ideal fluid can be represented as [Jensen et al., 2011]

$$
\nabla^{2} \psi-\frac{1}{c_{p}^{2}} \frac{\partial^{2} \psi}{\partial t^{2}}=0
$$

in which $\nabla^{2}$ is the Laplace operator; $\psi$ denotes the fluid displacement potential, which can be defined by

$$
\boldsymbol{u}=\nabla \psi
$$

in which $\boldsymbol{u}$ denotes the fluid particle displacement. For a sinusoidal wave, the wave equation of seismic P-wave propagation in an ideal fluid can be further written as the Helmholtz equation [Lurton, 2002]:

$$
\nabla^{2} \psi=-\frac{\omega^{2}}{c_{p}^{2}} \psi
$$

where $\omega$ is the circular frequency of P-wave. Eq. (8) can be solved with the P-wave trail function [Wolf, 1985]:

$$
\psi=M_{p} \exp \left[\frac{i \omega}{c_{p}}\left(-l_{x} x-l_{y} y-l_{z} z\right)\right]
$$

where $M_{p}$ is the amplitude of $\mathrm{P}$-wave, $l_{x}, l_{y}$ and $l_{z}$ can be introduced as the propagation direction cosines in the Cartesian coordinate system and the wave equation is satisfied when $l_{x}^{2}+l_{y}{ }^{2}+l_{z}^{2}=1$. According to Eq. (9), the displacement vector in any direction can be expressed as

$$
u_{j}=-l_{j} M_{p} \frac{i \omega}{c_{p}} \exp \left[\frac{i \omega}{c_{p}}\left(-l_{x} x-l_{y} y-l_{z} z\right)\right]
$$

where $j$ represents $x, y$ or $z$.

Moreover, the stress tensors of a Newtonian fluid in the Cartesian coordinate system can be represented by [Batchelor, 2000]: 


$$
\sigma_{i j}=-p \delta_{i j}+\mu\left[\left(\frac{\partial v_{i}}{\partial x_{j}}+\frac{\partial v_{j}}{\partial x_{i}}\right)-\frac{2}{3} \delta_{i j} \nabla \cdot v\right]
$$

where $\delta_{i j}$ is the Delta function which equals 1 when $i=j$ and 0 when $i \neq j ; \mu$ is the coefficient of viscosity and equals zero under the ideal fluid assumption; $p$ denotes a measure of compressive stress in a flowing fluid, and it is a scalar whose value equals to the average compressive stress acting on the surface of an infinitesimal fluid particle. The fluid pressure $p$ can be derived from Eqs. (1), (4) and (7):

$$
p=-K \nabla^{2} \psi
$$

Substituting Eq. (9) into Eqs. (11) and (12), the fluid normal stresses induced by seismic P-wave excitation can be expressed as

$$
\sigma_{j j}=-K M_{p} \frac{\omega^{2}}{c_{p}^{2}} \exp \left[\frac{i \omega}{c_{p}^{2}}\left(-l_{x} x-l_{y} y-l_{z} z\right)\right]
$$

where $j$ represents the Cartesian coordinates $x, y$ or $z$. Thus, the earthquake induced fluid particle displacements and stresses are fully obtained by Eqs. (10) and (13).

2.2 The application of $1 \mathrm{D}$ wave propagation theory

It is well-known that the ground motion transfer functions of onshore sites can be derived based on the 1D wave propagation theory proposed by Wolf [1985]. However, the influence of water layer is not included in Wolf's theory and it only considers the effects of multiple soil layers. By combining with the hydrodynamics formulas presented above, the 1D wave propagation theory is employed to derive the transfer functions of an underwater rock site in this study.

Assuming the seismic P-wave propagates in the vertical $x$ - $z$ plane $\left(l_{y}=0, l_{x}{ }^{2}+l_{z}{ }^{2}=1\right)$ of the seawater layer, the fluid vertical displacement and normal stress expressed in Eqs. (10) and (13) are reformulated as:

$$
\begin{gathered}
u_{z}=-l_{z} M_{p} \frac{i \omega}{c_{p}^{*}} \exp \left[\frac{i \omega}{c_{p}^{*}}\left(-l_{x} x-l_{z} z\right)\right] \\
\sigma_{z z}=-K^{*} M_{p} \frac{\omega^{2}}{c_{p}^{* 2}} \exp \left[\frac{i \omega}{c_{p}^{* 2}}\left(-l_{x} x-l_{z} z\right)\right]
\end{gathered}
$$

where $K^{*}=K(1+2 \xi i)$ and $c_{p}^{*}=c_{p} \sqrt{1+2 \xi i}$ are the complex values of the fluid bulk modulus and $\mathrm{P}$-wave velocity in which the effect of the hysteretic damping ratio $\xi$ is taken into account.

By analyzing the relationship between the seismic P-wave induced fluid normal stresses and displacements on the top and bottom of a seawater layer, the dynamic stiffness matrix of the seawater layer can be derived by utilizing the approach presented in Wolf's 1D wave propagation theory [Wolf, 1985; Li et al., 2015]:

$$
\left\{\begin{array}{l}
F_{z 1} \\
F_{z 2}
\end{array}\right\}=\left[S_{P}^{W}\right]\left\{\begin{array}{l}
u_{z 1} \\
u_{z 2}
\end{array}\right\}=\frac{K^{*} \omega}{l_{x} s c_{p}^{*} \sin k s d}\left[\begin{array}{cc}
\cos k s d & -1 \\
-1 & \cos k s d
\end{array}\right]\left\{\begin{array}{l}
u_{z 1} \\
u_{z 2}
\end{array}\right\}
$$

where $F_{z 1}, F_{z 2}$ and $u_{z 1}, u_{z 2}$ are the vertical load amplitudes and fluid displacements at the top and bottom of the seawater layer, respectively; $l_{x}$ and $s$ are the cosine and tangent values of 
incident angle and $k$ is the wave number. As shown, the dynamic stiffness matrix $\left[S_{P}^{W}\right]$ is symmetric and is determined by the circular frequency $\omega$, the incident angle $\beta_{p}$ and the properties of seawater layer, namely the bulk modulus $K$, the density $\rho$, the water depth $d$ and the damping ratio $\xi$.

Based on the derived dynamic stiffness matrix of seawater layer, the transfer functions of a base rock site under a seawater layer can be derived. The base rock motions are assumed to be composed of out-of-plane SH-wave or in-plane coupled P- and SV-waves and propagating into the seawater with respective incident angles. The dynamic equilibrium equation of the underwater rock site can be written in the frequency domain as [Wolf, 1985]

$$
\left[S_{S H}\right]\left\{u_{S H}\right\}=\left\{P_{S H}\right\} \text { or }\left[S_{P-S V}\right]\left\{u_{P-S V}\right\}=\left\{P_{P-S V}\right\}
$$

where $\left\{u_{S H}\right\},\left\{u_{P-S V}\right\}$ and $\left\{P_{S H}\right\},\left\{P_{P-S V}\right\}$ denote the displacements and load vectors of the in-plane SH-wave and out-of-plane coupled $\mathrm{P}$ - and SV-waves, respectively; For the underwater base rock site, the total dynamic stiffness matrix $\left[S_{P-S V}\right]$ can be obtained by assembling the stiffness matrix of the base rock with that of the seawater layer. It should be noted that the total dynamic stiffness matrix for the out-of-plane $\mathrm{SH}$-wave, namely $\left[S_{S H}\right]$, is not influenced by seawater since it cannot transmit $S$-wave.

The schematic view of in-plane $\mathrm{P}$ - and $\mathrm{SV}$-waves propagating in an underwater rock site is illustrated in Fig. 1, in which $M_{p}, M_{s v}$ and $N_{p}, N_{s v}$ denote the amplitudes of incident and reflected P- and SV-waves, and the superscripts $W$ and $R$ denote the water layer and base rock, respectively. To keep the identical wave number of $\mathrm{P}$ - and $\mathrm{SV}$-waves, the wave apparent velocity $c$ is formulated as

$$
c=c_{p}^{* R} / l_{x}^{R}=c_{s v}^{* R} / m_{x}^{R}=c_{p}^{* W} / l_{x}^{W}
$$

where $l_{x}$ and $m_{x}$ are the direction cosines of the incident $\mathrm{P}$ - and $\mathrm{SV}$-waves, respectively. Thus, with an assumed base rock P-wave incident angle $\beta_{p}^{R}$, the inclined angles of base rock $\mathrm{SV}$-wave and seawater P-wave $\left(\beta_{s v}^{R}\right.$ and $\left.\beta_{p}^{W}\right)$ can be determined.

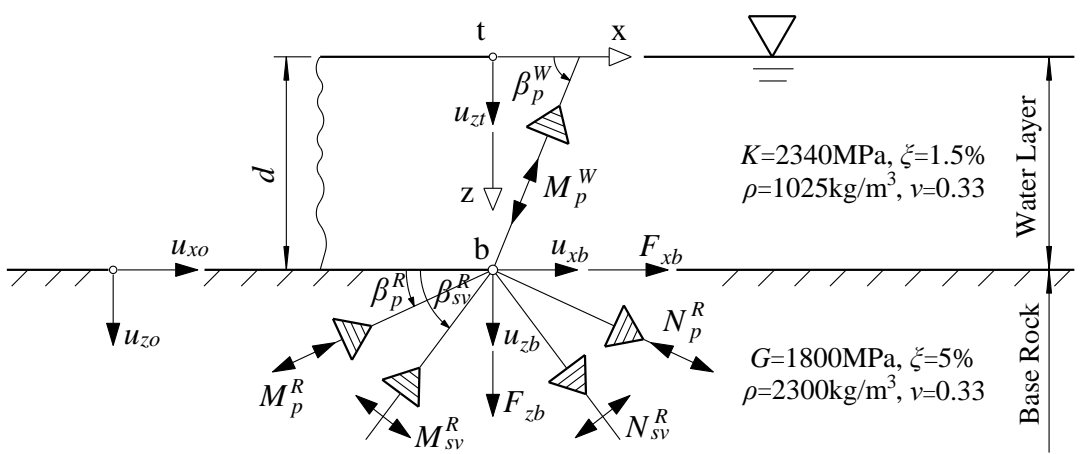

FIGURE 1 An underwater rock site with nomenclature for in-plane coupled P- and SV-waves

As presented by Wolf [1985], the dynamic stiffness matrix of the base rock for the in-plane $\mathrm{P}$ - and $\mathrm{SV}$-waves is represented as

$$
\left\{\begin{array}{c}
F_{x o} \\
i F_{z o}
\end{array}\right\}=\left[S_{P-S V}^{R}\right]\left\{\begin{array}{c}
u_{x o} \\
i u_{z o}
\end{array}\right\}=k G^{*}\left[\begin{array}{cc}
\frac{i s^{\prime}\left(1+t^{\prime 2}\right)}{1+s^{\prime} t^{\prime}} & 2-\frac{1+t^{\prime 2}}{1+s^{\prime} t^{\prime}} \\
2-\frac{1+t^{\prime 2}}{1+s^{\prime} t^{\prime}} & \frac{i t^{\prime}\left(1+t^{\prime 2}\right)}{1+s^{\prime} t^{\prime}}
\end{array}\right]\left\{\begin{array}{c}
u_{x o} \\
i u_{z o}
\end{array}\right\}
$$


where the subscript $o$ denotes the outcropping, namely the free surface of base rock [Wolf, 1985]; $G^{*}$ is the shear modulus of base rock; the values $s^{\prime}$ and $t^{\prime}$ equal to $\tan \beta_{p}^{R}$ and $\tan \beta_{s v}^{R}$, respectively.

Assembling the derived dynamic stiffness matrix of seawater layer $\left[S_{P}^{W}\right]$ with that of the base rock $\left[S_{P S V}^{R}\right]$, the dynamic equilibrium equation of underwater rock site is written as

$$
\left[\begin{array}{ccc}
m / \tan k s d & 0 & -m / \sin k s d \\
0 & i k G^{*} n s^{\prime} & k G^{*}(2-n) \\
-m / \sin k s d & k G^{*}(2-n) & m / \tan k s d+i k G^{*} n t^{\prime}
\end{array}\right]\left\{\begin{array}{c}
i u_{z t} \\
u_{x b} \\
i u_{z b}
\end{array}\right\}=\left\{\begin{array}{c}
0 \\
F_{x b} \\
i F_{z b}
\end{array}\right\}
$$

in which

$$
m=\frac{K^{*} \omega}{l_{x}^{W} s c_{p}^{* W}} \text { and } n=\frac{1+t^{\prime 2}}{1+s^{\prime} t^{\prime}}
$$

where the subscript $t$ and $b$ denote the top and bottom of seawater layer, respectively. The load vector amplitudes at the bottom of the water layer $F_{x b}$ and $F_{z b}$ can be calculated by

$$
\left\{\begin{array}{c}
F_{x b} \\
i F_{z b}
\end{array}\right\}=\left[S_{P-S V}^{R}\right]\left\{\begin{array}{c}
u_{x o} \\
i u_{z o}
\end{array}\right\}
$$

where $\left[S_{P-S V}^{R}\right]$ is defined in Eq. (19), $u_{x o}$ and $u_{z o}$ are the outcropping motions in the $x$ - and $z$-directions, respectively. Combining Eq. (20) with (22), the vertical transfer function, namely the ratio of underwater base rock vertical motion $u_{z b}$ to outcropping vertical motion $u_{z o}$ is derived in the frequency domain as

$$
H_{z}(\omega)=\frac{u_{z b}}{u_{z o}}=\frac{1}{1+\frac{m n s^{\prime} \tan k s d}{k G^{*}(2-n)^{2}+k G^{*} n^{2} s^{\prime} t^{\prime}} \cdot i}
$$

and its modulus can be expressed as

$$
\left|H_{z}(\omega)\right|=\left|\frac{u_{z b}}{u_{z o}}\right|=\frac{1}{\sqrt{1+\left[\frac{m n s^{\prime} \tan k s d}{k G^{*}(2-n)^{2}+k G^{*} n^{2} s^{\prime} t^{\prime}}\right]^{2}}}
$$

It is obvious that $\left|H_{z}(\omega)\right| \leq 1$ and the modulus tends to zero when $\tan k s d \rightarrow \infty$, namely

$$
k s d=\frac{2 \pi f l_{x}^{W}}{c_{p}^{* W}}(-i) \sqrt{1-\frac{1}{l_{x}^{W 2}}} \cdot d=\frac{2 \pi f d}{c_{p}^{* W}} \sin \beta_{p}^{W}=N \cdot \frac{\pi}{2},(N=1,3,5 \cdots)
$$

where $N$ is an odd number. The resonant frequencies of P-wave in seawater can be obtained according to Eq. (25):

$$
f_{N}=N \frac{c_{p}^{* W}}{4 d \sin \beta_{p}^{W}},(N=1,3,5 \cdots)
$$

At these resonant frequencies, a phase change will occur between the upward propagating and the downward reflected P-waves at the interface of seawater and base rock, and lead to a destructive interference in the P-wave motion [Boore and Smith, 1999]. This effect will finally result in a significant reduction in the vertical seafloor motion. As shown in Eq. (26), the $\mathrm{P}$-wave resonant frequencies of seawater depend on the water depth $d$, the $\mathrm{P}$-wave velocity $c_{p}^{* W}$ and the incident angle $\beta_{p}^{W}$.

Analogously, the horizontal transfer function of the rock site overlaid with seawater can also be derived based on Eq. (20). Fig. 2 plots the site transfer functions for the horizontal 
and vertical in-plane motions, which are calculated based on the site parameters given in Fig. 1. The P-wave incident angle in the base rock is assumed to be $\beta_{p}^{R}=60^{\circ}, \beta_{s v}^{R}$ and $\beta_{p}^{W}$ are respectively calculated to be $75.4^{\circ}$ and $62.3^{\circ}$ according to Eq. (18). Four different depths of seawater (i.e., $d=20,40,80,160 \mathrm{~m}$ ) are considered to study its effect on the site transfer functions. As shown in Fig. 2, both of the horizontal and vertical transfer functions are reduced at P-wave resonant frequencies of seawater. Taking $d=20 \mathrm{~m}$ as an example, a minimum value is obtained at the fundamental resonant frequency of $21.3 \mathrm{~Hz}$, which is calculated based on Eq. (26). The fundamental P-wave resonant frequency decreases with the increase of seawater depth. It can be observed that the transfer functions in the horizontal direction are much larger than those in the vertical direction and even the minimum values are very close to 1 , which indicates that the seawater layer has almost no effect on the horizontal in-plane motions. However, the vertical in-plane motion is significantly suppressed at the P-wave resonant frequencies as the values of vertical transfer functions approach to zero at these frequencies. This is owing to the destructive interference effect of P-waves at the base rock and seawater interface as discussed above. Moreover, due to the effect of material damping, the extreme values of site transfer functions decrease slightly with the increase of frequency.

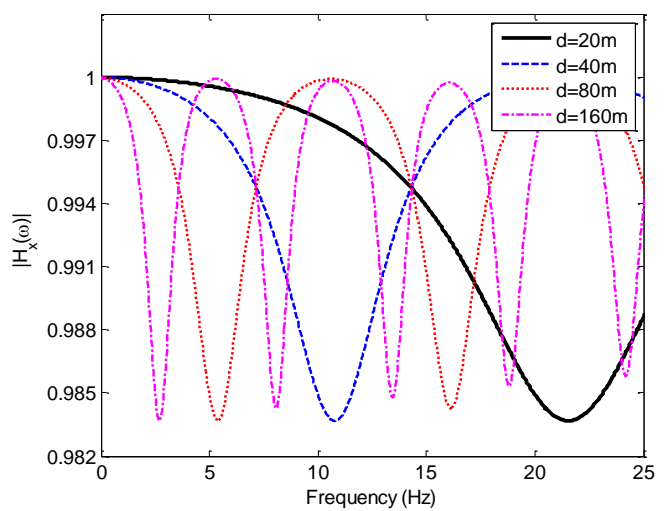

b

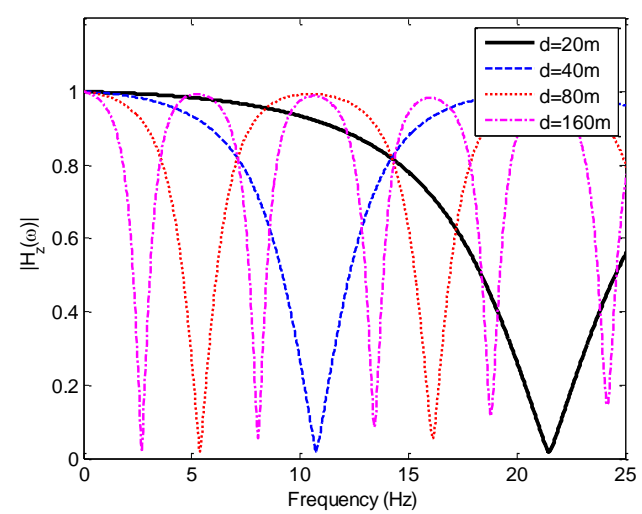

FIGURE 2 Transfer functions of the base rock site overlaid with seawater (a) Horizontal in-plane motion; (b) Vertical in-plane motion

\subsection{Comparison with previous transfer function models}

To validate the above derivations, the vertical transfer function model of underwater rock site proposed in this paper is compared with those suggested in two previous studies [Crouse and Quilter, 1991; Boore and Smith, 1999]. The model presented by Crouse and Quilter [1991] is derived based on the assumption that the seismic P-waves in an elastic half-space vertically propagate into the upper water layer. It should be noted that in this model neither the contribution of S-wave in the vertical motion nor the effect of seismic wave inclined angle is considered. Therefore this model can be considered as a special case of the current model derived in this paper. The model presented by Boore and Smith [1999] is computed for an offshore site with different earthquake fault types by using the wavenumber integration method. In the latter model, only the fundamental resonant frequency is considered, while the model derived by Crouse and Quilter [1991] and the present model can include high vibration modes. For comparison, the properties of seawater and base rock illustrated in Fig. 1 are set to be aligned with the previous studies. The seismic P-waves are assumed to be vertically incident into the seawater layer $\left(\beta_{p}^{R}=\beta_{s v}^{R}=\beta_{p}^{W}=90^{\circ}\right)$ and the water depth is $60 \mathrm{~m}$. 
The comparison results are shown in Fig. 3, from which one can observe that the vertical transfer function model proposed in this study are in good agreement with the previous models. Since the model by Boore and Smith [1999] can only include the fundamental resonant frequency $(6.25 \mathrm{~Hz})$, comparison with this model is possible only at the fundamental mode while comparisons at the multiple modes, i.e., $6.25 \mathrm{~Hz}, 18.75 \mathrm{~Hz}, \cdots$ are made with the model presented by Crouse and Quilter [1991]. As shown, the minimum of vertical transfer function calculated by the proposed model is slightly higher than that calculated by the model of Crouse and Quilter [1991]. This is because in their model, the damping ratios of the base rock and the water layer are both neglected, which results in the minimum of the vertical transfer function equal to 0 at the resonant frequencies. Nonetheless, the comparisons shown in Fig. 3 demonstrate that the proposed model gives good prediction of the seismic wave transfer function of underwater sites.

It should be noted that if the $\mathrm{P}$-wave is not vertically transmitting into the seawater, namely $\beta_{p}^{W}<90^{\circ}$, the fundamental resonant frequency will be larger than $6.25 \mathrm{~Hz}$. For illustration, the vertical transfer function of the same underwater base rock site with inclined incident P-waves $\left(\beta_{p}^{W}=60^{\circ}\right)$ is also plotted in Fig. 3. The fundamental resonant frequency is calculated to be $7.22 \mathrm{~Hz}$ for the case with inclined incidence. It can be seen that the proposed model can take into consideration the effect of incident angle and damping ratio, as well as the contribution of SV-wave. Therefore, the derived model can be utilized to more realistically represent the effect of seawater on seismic motions of subsea sites.

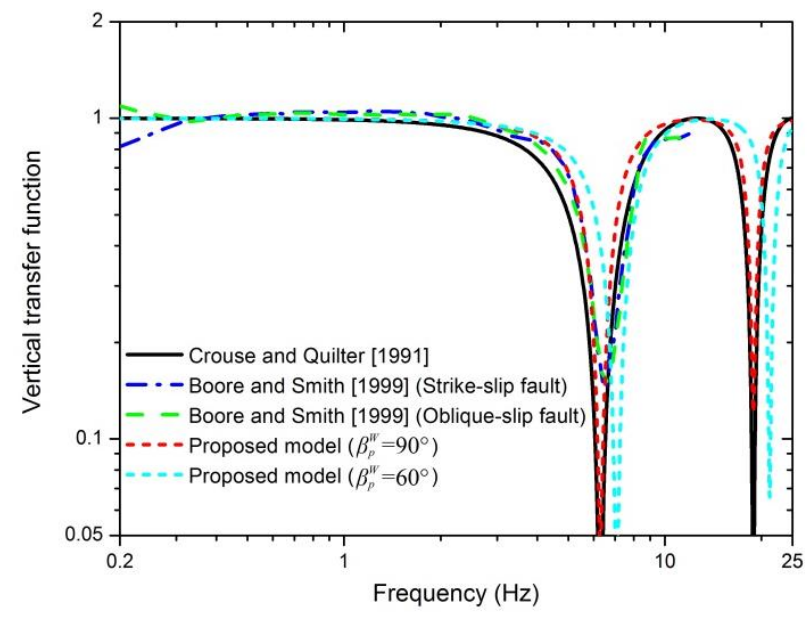

FIGURE 3 Comparison of the proposed vertical transfer function model for the underwater site with those proposed in previous studies

\section{Seafloor motion transfer functions of a layered subsea site}

For an actual complex offshore site, there exists a widespread of fully or nearly saturated sediments underlying the seawater. These porous sediments can significantly influence the propagation of seismic P-wave and thus affect the site amplification of seafloor motions. It has been proved that two kinds of P-waves with different propagation velocities can be generated in the two-phase porous soils [Biot, 1956a,b]. However, for most seismic waves which remain in the relatively low frequency range, the P-wave with lower velocity can be neglected [Yang and Sato, 2000]. Therefore, only the S-wave and the P-wave with higher velocity need to be concerned in the seismic engineering problems. As suggested by Yang and Sato [2000], the Poisson's ratio and P-wave velocity of porous soils can be estimated by 


$$
\begin{gathered}
v=\frac{1}{2} \frac{\alpha^{2} M / G+2 v^{\prime} /\left(1-2 v^{\prime}\right)}{\alpha^{2} M / G+1 /\left(1-2 v^{\prime}\right)} \\
V_{p}=\sqrt{\frac{\lambda+2 G+\alpha^{2} M}{\rho}}
\end{gathered}
$$

in which $v^{\prime}, \lambda$ and $G$ are the Poisson's ratio, Lame constant and shear modulus of the soil skeleton, respectively; $\rho=(1-n) \rho_{s}+n \rho_{f}$, with $\rho_{s}, \rho_{f}$ and $n$ denoting the soil grain density, the pore fluid density and the porosity, respectively; $\alpha$ and $M$ are parameters related to the compressibilities of soil grains and pore fluid, which can be expressed as

$$
\alpha=1-\frac{K_{b}}{K_{s}}, M=\frac{K_{s}^{2}}{K_{d}-K_{b}}, K_{d}=K_{s}\left[1+n\left(\frac{K_{s}}{K_{f}}-1\right)\right]
$$

where $K_{s}$ and $K_{b}$ are the bulk moduli of soil grains and skeleton, respectively; and $K_{f}$ denotes the bulk modulus of the pore fluid, which is defined as [Verruijt, 1969]

$$
K_{f}=\frac{1}{1 / K_{w}+\left(1-S_{r}\right) / p_{a}}
$$

where $K_{w}$ denotes the bulk modulus of pore water; $S_{r}$ is the degree of saturation and $p_{a}$ is the absolute fluid pressure.

The influence of water saturation on the P-wave propagation in porous soils is not considered in Wolf's 1D wave propagation theory. In the present study, the Poisson's ratio and P-wave velocity model for porous soils, namely Eqs. (27) and (28), are substituted into the dynamic stiffness matrices of soil layers to consider the soil saturation effect. The total dynamic stiffness matrix of an offshore site, which is assumed to consist of the base rock, the porous soil layers and an upper seawater layer, can be assembled based on the derived stiffness matrix of the seawater layer and those of the soil layers and base rock. The seafloor motion transfer functions can be calculated by solving Eq. (17) at every discrete frequency. It needs to be emphasized that the site amplification of horizontal out-of-plane motion, which is assumed to solely consist of SH-wave, will not be influenced by seawater or pore fluids, since neither of these two factors can affect the propagation of S-wave.

As concluded in the study by Yang and Sato [2000] and Wang and Hao [2002], the ground motion site amplification effect of porous soil layers will be substantially affected even if the water saturation level is slightly below full saturation. Moreover, it has been reported that the nearly saturated sandy seabed sediments $\left(S_{r}=0.97-1.0\right)$ can exist in the coastal zones in engineering practice [Magda, 2000], although the soil layers have been overlaid by seawater for a very long period. Thereby, it is necessary to conduct a parametrical analysis to investigate the effect of degree of saturation on the offshore site transfer functions. Fig. 4 shows a simple offshore site with a soil layer and a seawater layer overlying on the base rock, the corresponding parameters are also illustrated. The depth of seawater layer and soil layer are assumed to be $60 \mathrm{~m}$ and $20 \mathrm{~m}$, respectively. The incident angle of P-wave on the base rock is assumed to be $60^{\circ}$. A total of five degree of saturation values are considered, i.e., $S_{r}=1$, $99.9 \%, 99.5 \%, 99 \%$ and $98 \%$. It should be noted that the Poisson's ratio given in Fig. 4 is for the soil skeleton, the Poisson's ratio of the porous soil layer can be calculated using the skeleton Poisson's ratio and the assumed soil saturation level based on Eq. (27). The calculated offshore site transfer functions for horizontal and vertical in-plane motions are plotted in Fig. 5. 


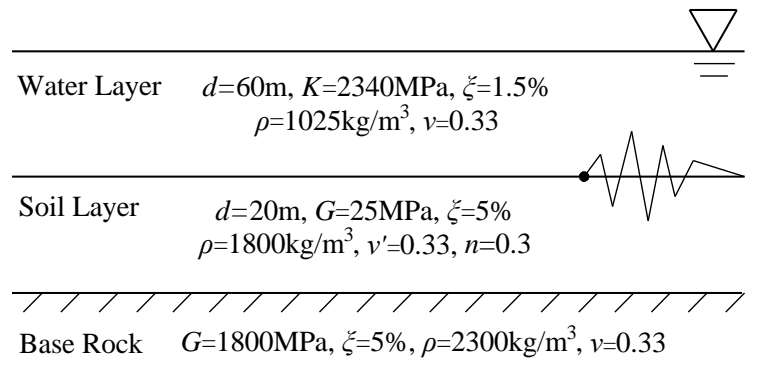

FIGURE 4 Schematic view of a simple layered offshore site

a

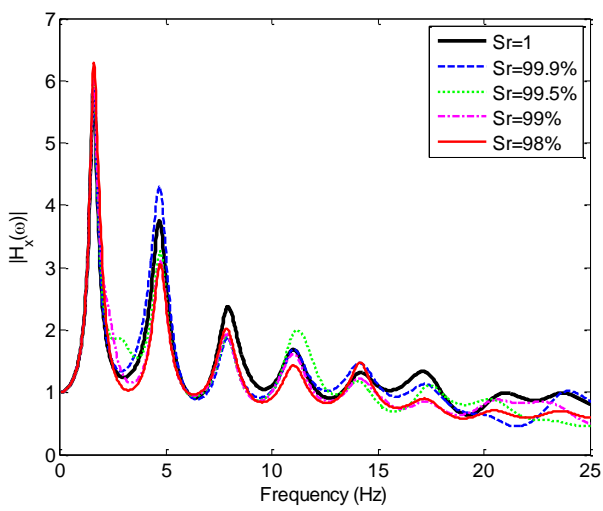

$\mathrm{b}$

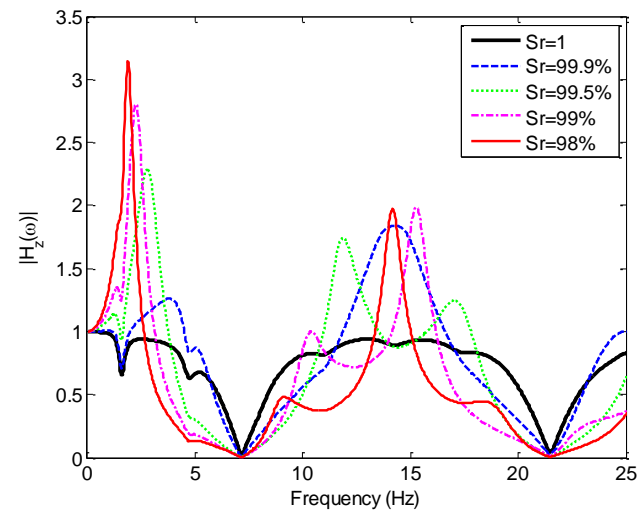

FIGURE 5 Influence of degree of saturation on the offshore site transfer functions (a) Horizontal in-plane motion; (b) Vertical in-plane motion

As can be observed, the horizontal transfer functions with different saturation degrees are almost the same, indicating that the degree of saturation has little effect on the horizontal in-plane motion. However, the vertical transfer function is significantly influenced by the degree of saturation, even a slight decrease below full saturation can lead to a considerable increase in the peak values of vertical transfer function. For the fully saturated case $\left(S_{r}=1\right)$, the vertical seafloor motion is always smaller than the vertical outcropping motion in the frequency range from 0 to $25 \mathrm{~Hz}$. With the decrease of $S_{r}$, the peak value of vertical transfer function is significantly increased and the predominant frequency is shifted to a lower frequency range. This is because $\mathrm{P}$-wave has a significant contribution to the vertical in-plane motion and a substantial decrease of the P-wave velocity can be induced by a small proportion of air in the pore fluid. Moreover, the vertical in-plane motions are suppressed at the resonant frequencies of the upper seawater layer, as previously discussed in the case of a seawater layer overlying on the base rock.

It can be inferred from Eqs. (28) to (30) that the porous soil P-wave velocity is significantly affected by the depth of overlying seawater, since it directly determines the pore fluid pressure in porous soil layers. In this study, the effect of seawater depth on the seafloor motion transfer functions is investigated by changing the seawater depth of the example offshore site shown in Fig. 4. The depth of the soil layer is fixed at $20 \mathrm{~m}$ and the seawater depth is assumed to be 0 (i.e., without seawater), 20, 40, 80 and $160 \mathrm{~m}$, respectively. The absolute fluid pressure in the subsea soil layer, i.e., $p_{a}$ in Eq. (30), increases with the seawater depth. For all these five cases, the degree of saturation of the soil layer is assumed to be 99.9\%. The seafloor motion transfer functions of the sites with different seawater depths are shown in Fig. 6.

It can be observed that the horizontal transfer functions of the sites with different seawater 
depths are very similar, implying that the depth of seawater has almost no effect on the horizontal in-plane motion. Nonetheless, the vertical transfer functions are evidently affected by the seawater depth. Compared with the site without seawater $(d=0)$, the vertical transfer functions of the subsea sites are much smaller. With the increase of the water depth, the peak value of the transfer functions decreases and the dominant frequency moves towards the lower frequency range. This is because the pore fluid pressure increases with the seawater depth and the P-wave velocity in the porous soil layer is increased. Moreover, the vertical transfer functions reach the minimum values at different $\mathrm{P}$-wave resonant frequencies corresponding to the different depths of overlying seawater layer.

a

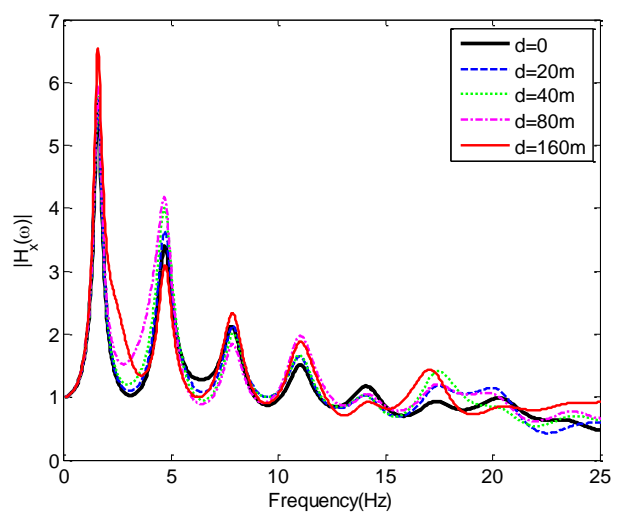

b

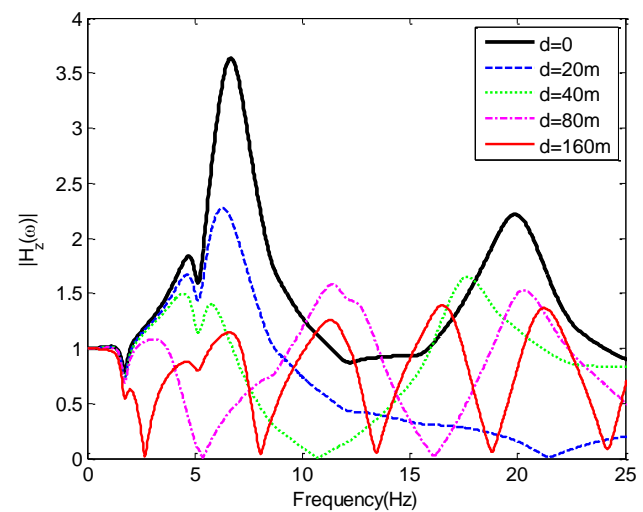

FIGURE 6 Effect of seawater depth on the offshore site transfer functions (a) Horizontal in-plane motion; (b) Vertical in-plane motion

The above results indicate that the degree of saturation and seawater depth both have a significant effect on the transfer functions for the vertical seafloor in-plane motions. The derived offshore site transfer functions can be utilized to achieve reasonable simulations of seafloor seismic motions.

\section{Simulation of spatially correlated seismic motions at onshore and offshore sites}

Based on the derived offshore site transfer functions, the spatially varying seafloor seismic motions are simulated using the SRM in this section. A coastal non-uniform site with an onshore station (site 1) and an offshore station (site 2) is selected as an example, as shown in Fig. 7, in which $d$ represents the layer depth, $G$ shear modulus, $K$ bulk modulus of seawater, $\rho$ density, $v$ calculated Poisson's ratio of the porous soils, $\xi$ damping ratio, $n$ porosity and $S_{r}$ degree of saturation. The spatially correlated seismic motions on the surfaces of the onshore seafloor sites are to be synthesized. 


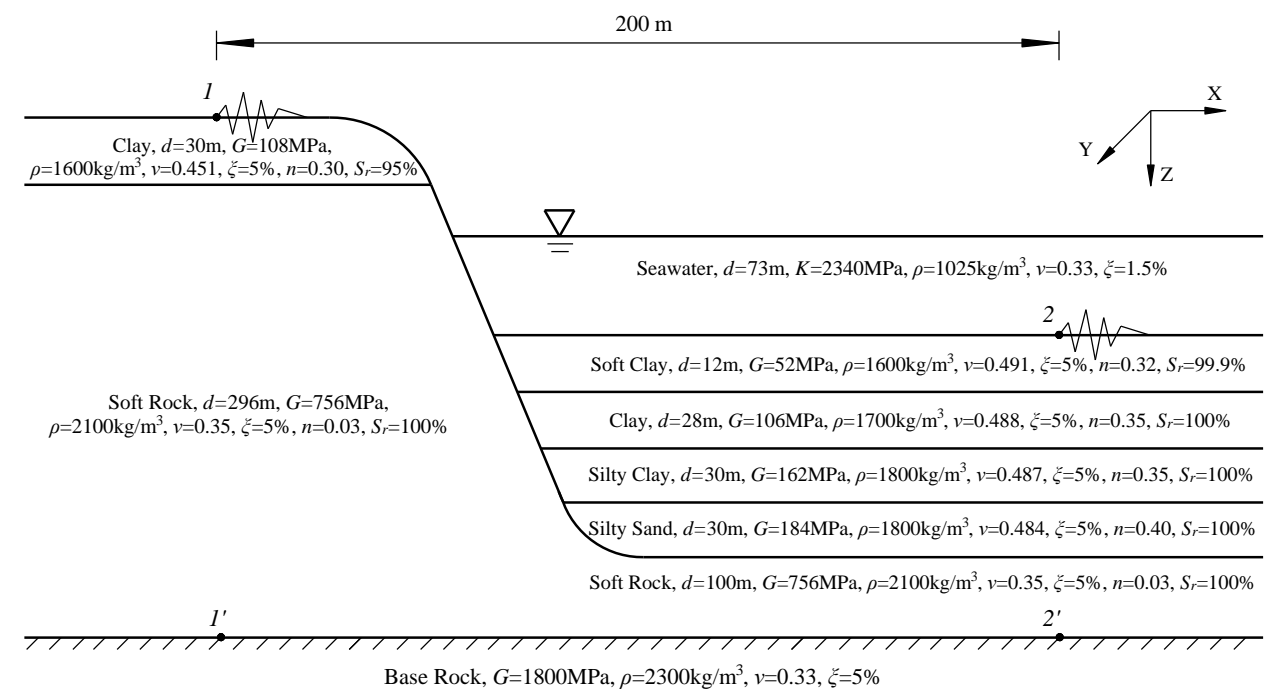

FIGURE 7 Spatially distributed onshore and offshore sites located in a coastal area

\subsection{Simulation approach based on SRM}

In this study, the three-dimensional base rock motions are assumed to consist of out-of-plane horizontal (Y-direction in Fig. 7) SH-wave or in-plane horizontal (X-direction) and vertical (Z-direction) coupled P- and SV-waves and propagate into the site with respective incident angles. Since the fault distance is supposedly much larger than the separation distance between the two points on the base rock (1' and 2' in Fig. 7), it is reasonable to assume that the spatially correlated base rock motions have the same power spectral density (PSD) functions since the distance between points $1^{\prime}$ and $2^{\prime}$ is normally much smaller than that between the two points ( 1 ' and $2^{\prime}$ ) and the seismic epicenter. Here, the base rock motions in three directions are all modeled by the filtered Tajimi-Kanai PSD function [Clough and Penzien, 1993]:

$$
S_{b r}(\omega)=\left|H_{P}(\omega)\right| S_{g}(\omega)=\frac{\omega^{4}}{\left(\omega_{f}^{2}-\omega^{2}\right)^{2}+4 \xi_{f}^{2} \omega_{f}^{2} \omega^{2}} \frac{\omega_{g}^{4}+4 \xi_{g}^{2} \omega_{g}^{2} \omega^{2}}{\left(\omega_{g}^{2}-\omega^{2}\right)^{2}+4 \xi_{g}^{2} \omega_{g}^{2} \omega^{2}} S_{0}
$$

in which $S_{b r}(\omega)$ represents the ground motion PSD function on the base rock; $\left|H_{P}(\omega)\right|$ is a high pass filter function and $S_{g}(\omega)$ is the Tajimi-Kanai PSD function; $\omega_{f}, \omega_{g}$ and $\xi_{f}, \xi_{g}$ are the central frequencies and damping ratios of the high pass filter and Tajimi-Kanai PSD function [Tajimi, 1960], respectively. The parameters for the horizontal base rock motions are set to be $\omega_{f}=0.5 \pi \mathrm{rad} / \mathrm{s}, \omega_{g}=10 \pi \mathrm{rad} / \mathrm{s}, \xi_{f}=\xi_{g}=0.6$ and $S_{0}=0.0031 \mathrm{~m}^{2} / \mathrm{s}^{3}$, which correspond to ground motion time series with duration of $40 \mathrm{~s}$, peak ground acceleration (PGA) of $0.2 \mathrm{~g}$ and peak ground displacement (PGD) of $0.084 \mathrm{~m}$ according to the standard random vibration method [Der Kiureghian, 1980]. Moreover, although it has been demonstrated in many previous studies that the vertical-to-horizontal $(\mathrm{V} / \mathrm{H})$ spectral ratio of the seismic motions are strongly dependent on the spectral period and the distance from causative fault [Bozorgnia and Campbell, 2004], a constant V/H ratio of 1/2 recommended by the American Petroleum Institute [RP 2A-WSD, 2000] is employed in the seismic analysis of long-period offshore platforms. Here, the response spectrum amplitude of the base rock vertical motion is assumed to be $1 / 2$ of that of the horizontal component. Since PSD is proportional to the square of response spectrum, the vertical to horizontal ratio of the base rock PSD function is set to be $1 / 4$ in the simulation. 
Considering only the linear response of each layer, the auto PSD functions of the three-dimensional seismic motions on the onshore and seafloor sites (i.e., sites 1 and 2 in Fig.7) can be expressed as [Hao and Chouw, 2006]

$$
S_{11}(\omega)=\left|H_{1}(i \omega)\right|^{2} S_{b r}(\omega) \text { and } S_{22}(\omega)=\left|H_{2}(i \omega)\right|^{2} S_{b r}(\omega)
$$

where $H_{1}(i \omega)$ and $H_{2}(i \omega)$ are respectively the three-dimensional transfer functions of the onshore and seafloor sites, which can be calculated by considering the effects of soil saturation and seawater as discussed above.

The cross PSD function between seismic motions on sites 1 and 2 can be expressed as [Hao and Chouw, 2006]

$$
S_{12}(\omega)=H_{1}(i \omega) H_{2}^{*}(i \omega) \gamma_{1^{\prime} 2^{\prime}}(i \omega) S_{b r}(\omega)
$$

where the superscript ' $*$ ' denotes complex conjugate; $\gamma_{1^{\prime} 2^{\prime}}(i \omega)$ is the coherency loss function between the spatial ground motions on the base rock. The model proposed by Sobczyk [40] is used to represent the coherency loss between the base rock motions:

$$
\gamma_{1^{\prime} 2^{\prime}}(i \omega)=\left|\gamma_{1^{\prime} 2^{\prime}}(i \omega)\right| \exp \left(-i \omega d_{1^{\prime} 2^{\prime}} / v_{a p p}\right)=\exp \left(-\beta \omega d_{1^{\prime} 2^{\prime}}^{2} / v_{a p p}\right) \cdot \exp \left(-i \omega d_{1^{\prime} 2^{\prime}} / v_{a p p}\right)
$$

where $\left|\gamma_{1^{\prime 2} 2^{\prime}}(i \omega)\right|$ denotes the lagged coherency; $d_{1^{\prime 2} 2^{\prime}}$ is the distance between sites $1^{\prime}$ and 2 ', and $d_{1^{\prime} 2^{\prime}}=200 \mathrm{~m}$ is assumed; $v_{a p p}$ is the apparent wave velocity on the base rock; $\beta$ is a coefficient that determines the level of coherency loss and $\beta=0.0005$ is employed in this paper to represent highly correlated motions. It should be noted that seismic motions are correlated with each other not only in the same direction between separated stations but also in the bi- or tri-orthogonal directions at one or multiple stations [Hong and Liu, 2014]. However, investigating the correlation between different components of earthquake motions is out the scope of current study, only the correlations between the ground motions in the same directions at sites 1' and 2' are modeled by Eq. (34).

The ground motion PSD function matrix at sites 1 and 2 can be assembled by using the auto and cross PSD functions as:

$$
S(i \omega)=\left[\begin{array}{ll}
S_{11}(\omega) & S_{12}(i \omega) \\
S_{21}(i \omega) & S_{22}(\omega)
\end{array}\right]=L(i \omega) L^{H}(i \omega)
$$

where $S(i \omega)$ is a positive definite and Hermitian matrix, which can always be decomposed into a complex lower triangular matrix $L(i \omega)$ and its Hermitian matrix $L^{H}(i \omega)$; the terms in $L(i \omega)$ can be calculated by [Hao et al., 1989]

$$
L_{j j}(\omega)=\left[S_{j j}(\omega)-\sum_{k=1}^{j-1} S_{j k}(i \omega) S_{j k}^{*}(i \omega)\right]^{1 / 2} \text { and } L_{j k}(i \omega)=\frac{S_{j k}(i \omega)-\sum_{l=1}^{j-1} S_{j l}(i \omega) S_{k l}^{*}(i \omega)}{S_{k k}(\omega)}
$$

where $j=k=1$ or 2 . Based on the fast Fourier transform technique, the spatial correlated ground motions at sites 1 and 2 can be generated in the frequency domain as

$$
U_{j}\left(i \omega_{n}\right)=\sum_{m=1}^{j} B_{j m}\left(\omega_{n}\right)\left[\cos \alpha_{j m}\left(\omega_{n}\right)+i \sin \alpha_{j m}\left(\omega_{n}\right)\right], n=1,2, \cdots, N
$$

where 


$$
B_{j m}\left(\omega_{n}\right)=\sqrt{\Delta \omega}\left|L_{j m}\left(i \omega_{n}\right)\right| \text { and } \alpha_{j m}\left(\omega_{n}\right)=\tan ^{-1}\left(\frac{\operatorname{Im}\left[L_{j m}\left(i \omega_{n}\right)\right]}{\operatorname{Re}\left[L_{j m}\left(i \omega_{n}\right)\right]}\right)+\varphi_{m n}\left(\omega_{n}\right), 0 \leq \omega \leq \omega_{N}
$$

are the amplitude and phase angle of simulated time series at the $n$th discrete frequency $\omega_{n}=n \Delta \omega$, where $\Delta \omega$ is the frequency resolution; $\varphi_{m n}\left(\omega_{n}\right)$ denotes a random phase angle that uniformly distributed in $[0,2 \pi], \varphi_{m n}$ and $\varphi_{r s}$ are statistically independent unless $m=r$ and $n=s$, and $\omega_{N}$ is the upper cut-off frequency.

By inverse transforming $U_{j}\left(i \omega_{n}\right)$ into the time domain, the corresponding ground motion time series $u_{j}(t)$ can be obtained. Nonstationary ground motions $w_{j}(t)$ are simulated by multiplying the generated stationary time series $u_{j}(t)$ with an envelope function $\zeta(t)$ :

$$
w_{j}(t)=\zeta(t) u_{j}(t)
$$

The Jennings envelope function is employed in this paper, which has the following form:

$$
\zeta(t)= \begin{cases}\left(t / t_{0}\right)^{2} & 0 \leq t \leq t_{0} \\ 1 & t_{0} \leq t \leq t_{n} \\ \exp \left[-0.155\left(t-t_{n}\right)\right] & t_{n} \leq t \leq T\end{cases}
$$

where $t_{0}$ and $t_{n}$ are assumed to be $5 \mathrm{~s}$ and $20 \mathrm{~s}$, respectively.

It should be noted that the filtered Tajimi-Kanai PSD function model and the Sobczyk model can be easily replaced with other available stochastic ground motion attenuation and coherency loss function models. Moreover, the simulation approach can be extended to simulate three-dimensional spatially correlated ground motions on more number of onshore and seafloor sites.

\subsection{Transfer functions of the example site}

The transfer functions of the onshore and offshore sites, i.e., $H_{1}(i \omega)$ and $H_{2}(i \omega)$ in Eqs. (32) and (33) are firstly calculated by considering the effects of soil saturation and seawater. The incident angles of out-of-plane SH wave and in-plane P-wave are both assumed to be $60^{\circ}$, the upper cut-off frequency is set to be $25 \mathrm{~Hz}$. The calculated three-dimensional transfer functions are plotted in Fig. 8, from which one can observe that both the onshore and offshore sites amplify the incident waves at corresponding site vibration frequencies. The fundamental frequency of the offshore site is lower than that of the onshore site because the offshore site is much softer. The two horizontal transfer functions $\left(H_{x}(i \omega)\right.$ and $\left.H_{y}(i \omega)\right)$ of the offshore site (site 2) are very similar. This is because seawater does not affect the propagation of S-wave, which dominates the horizontal motions. However, the offshore site transfer function for the vertical in-plane motion is significantly affected by the seawater. As compared to the onshore vertical motions, the vertical seafloor motions are substantially deamplified, especially at the resonant frequencies of the overlying seawater. The incident angle of $\mathrm{P}$-wave in seawater is calculated to be $64.5^{\circ}$ according to Eq. (18). Substituting the corresponding parameters into Eq. (26), the first two resonant frequencies can be obtained as $5.73 \mathrm{~Hz}$ and $17.19 \mathrm{~Hz}$. The vertical transfer function approaches to 0 at these two frequencies, as shown in Fig. 8. 

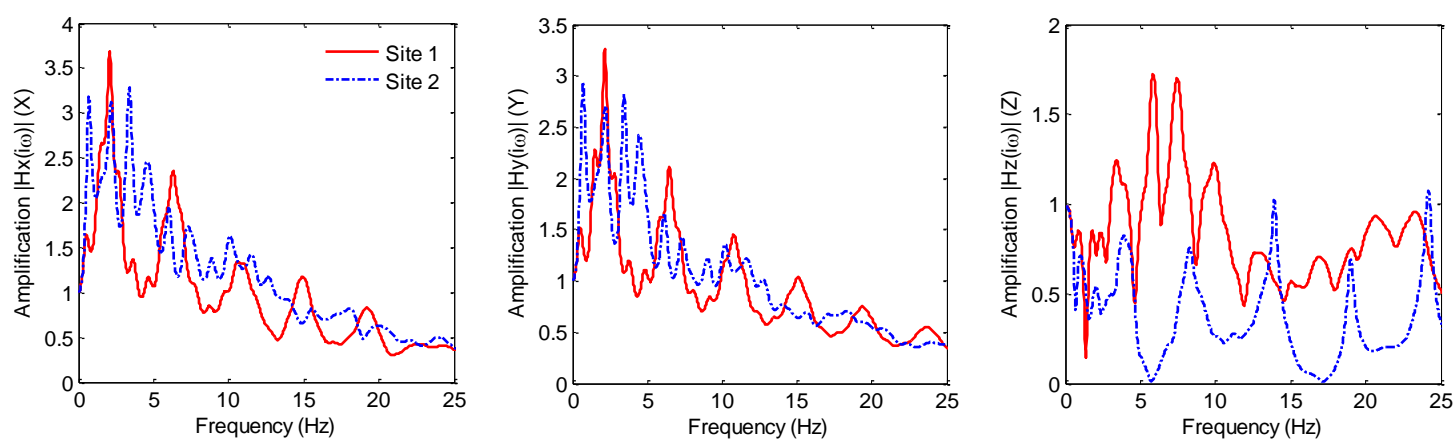

FIGURE 8 Three-dimensional onshore (site 1) and offshore (site 2) site transfer functions.

It is worth noting that if the effects of soil saturation and seawater are not considered when calculating the site transfer functions, only the effect of multiple soil layers can be considered in the calculation of auto and cross PSD functions of the onshore and offshore sites as expressed in Eqs. (32) and (33). Then the simulated spatially varying ground motions will be the same as those simulated by the approach presented by Bi and Hao [2012], in which the influences of soil saturation and seawater on the ground motion amplification effect of the multiple soil layers are not included. In other words, their work can be regarded a special case of the present study.

\subsection{Ground motion simulation}

In the simulation, the time duration and interval of the ground motions are assumed to be $40 \mathrm{~s}$ and $0.01 \mathrm{~s}$, respectively. The sampling frequency is set to be $100 \mathrm{~Hz}$ and the total number of points $N=4096$ is utilized in the FFT technique. The apparent wave velocity in the coherency loss model, i.e. $v_{a p p}$ in Eq. (34) is calculated to be $1768 \mathrm{~m} / \mathrm{s}$ according to the base rock property and the incident angle, which is assumed to be $60^{\circ}$.

The simulated horizontal spatially correlated acceleration and displacement time series on the free surface of base rock are shown in Fig. 9. The PGAs and PGDs of the generated base rock motions are $2.424,2.463 \mathrm{~m} / \mathrm{s}^{2}$ and $0.0853,0.0835 \mathrm{~m}$, respectively. These PGA and PGD values are very close to the calculated target PGA of $0.2 \mathrm{~g}$ and PGD of $0.084 \mathrm{~m}$ as mentioned above. Moreover, the PGA and PGD values and the characteristics of the generated base rock motions at the two sites are very similar as they are modelled with the same filtered Tajimi-Kanai PSD function. The comparison of PSD functions of simulated base rock motions and the model PSD function is shown in Fig.10, from which good agreements can be observed. Fig. 11 shows the comparison of the coherency loss between the simulated base rock motions at sites 1' and 2' with the Sobczyk model, good match is also observed.

a

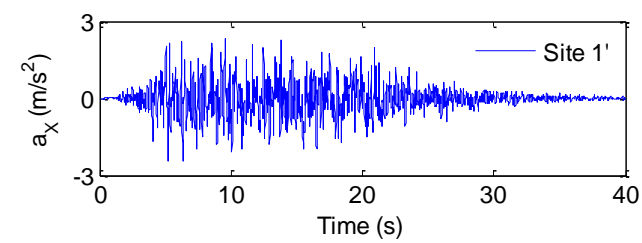

b

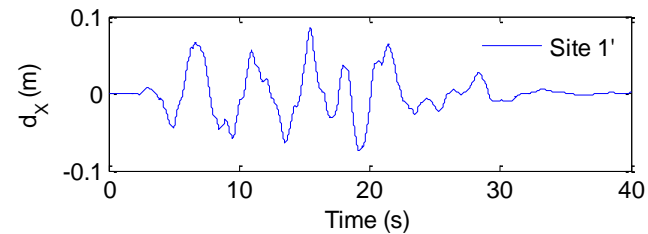

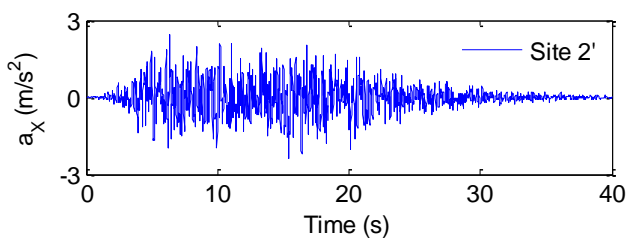

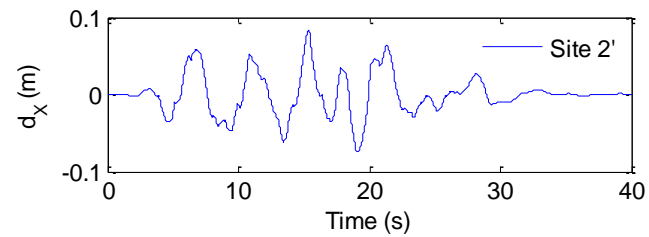

FIGURE 9 Generated horizontal spatially correlated ground motions on the free surface of 

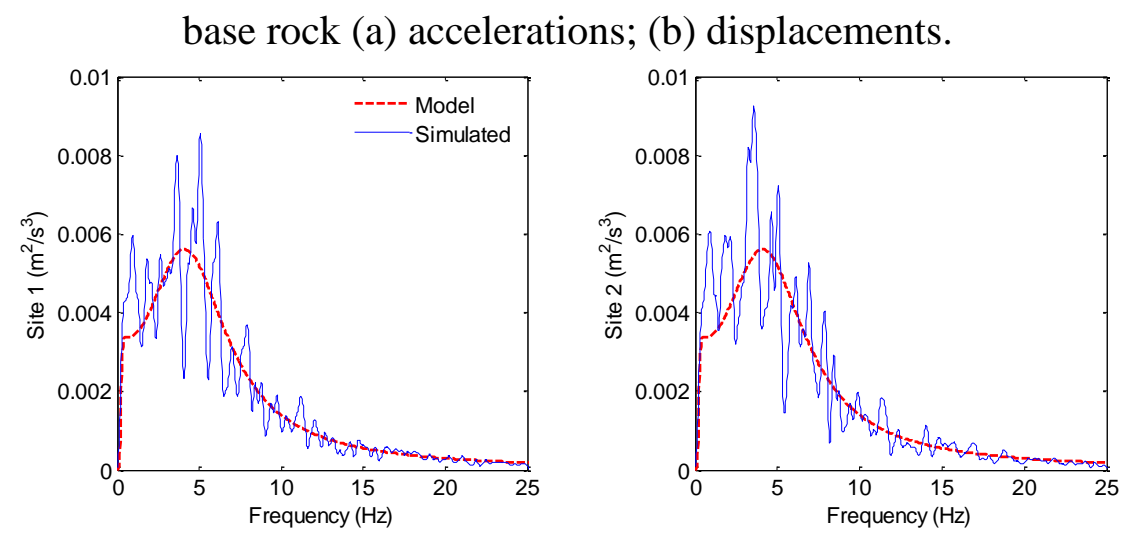

FIGURE 10 Comparison of PSD functions of the generated base rock horizontal accelerations with the model PSD function

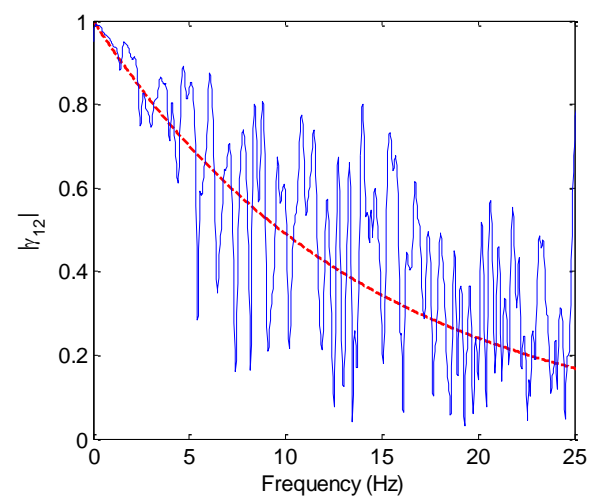

FIGURE 11 Comparison of coherency loss between the generated base rock horizontal accelerations with the coherency loss function model

Using the ground motion transfer functions and the simulation approach introduced above, the spatially correlated ground motions on the example sites shown in Fig. 7 are generated. The simulated three-dimensional acceleration and displacement time series on the surfaces of onshore (site 1) and offshore (site 2) sites are shown in Fig. 12. The horizontal PGAs and PGDs are $3.20,3.46 \mathrm{~m} / \mathrm{s}^{2}$ and $0.098,0.139 \mathrm{~m}$ for the onshore motions and $4.28,3.58 \mathrm{~m} / \mathrm{s}^{2}$ and $0.138,0.158 \mathrm{~m}$ for the seafloor motions, respectively. The vertical PGA and PGD are 2.28 $\mathrm{m} / \mathrm{s}^{2}$ and $0.072 \mathrm{~m}$ for the onshore motions and $1.23 \mathrm{~m} / \mathrm{s}^{2}$ and $0.070 \mathrm{~m}$ for the seafloor motions. The horizontal base rock motions are amplified by both of the two sites and the amplification effect of the softer offshore site is larger than that of the onshore site in the horizontal directions. However, the vertical PGA of the seafloor motion is much smaller than that of the onshore motion, owing to the suppression effect of vertical seafloor motions at the resonant frequencies of seawater layer, which can be directly reflected in the vertical offshore site transfer function as shown in Fig. 8. The difference between the vertical onshore and seafloor PGD values is slight as compared to that between the PGA values of the two sites. This is because the PGD value is more dependent on the ground motion energy in the low frequency range and the PSD functions of simulated vertical onshore and seafloor motions are very close at low frequencies, as can be observed in Fig. 13. The PSD functions of the simulated ground motions on sites 1 and 2 are compared with the respective theoretical PSD functions in Fig. 13. Good agreements can be observed. 
a
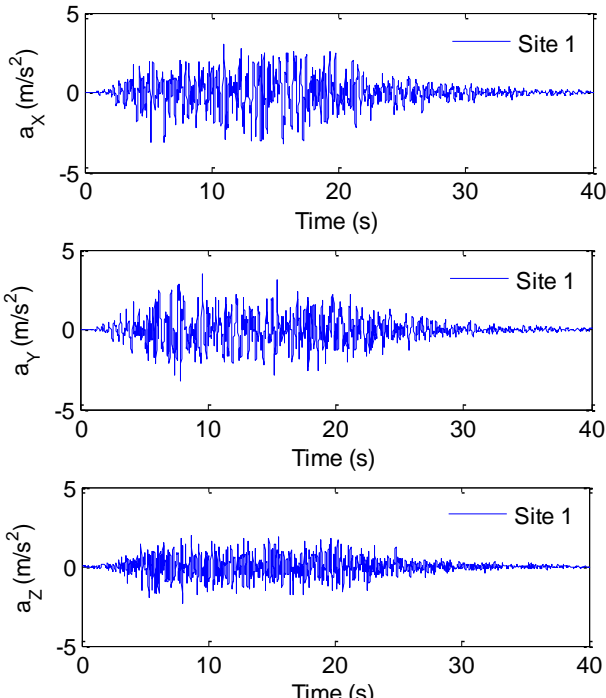

$\mathrm{b}$
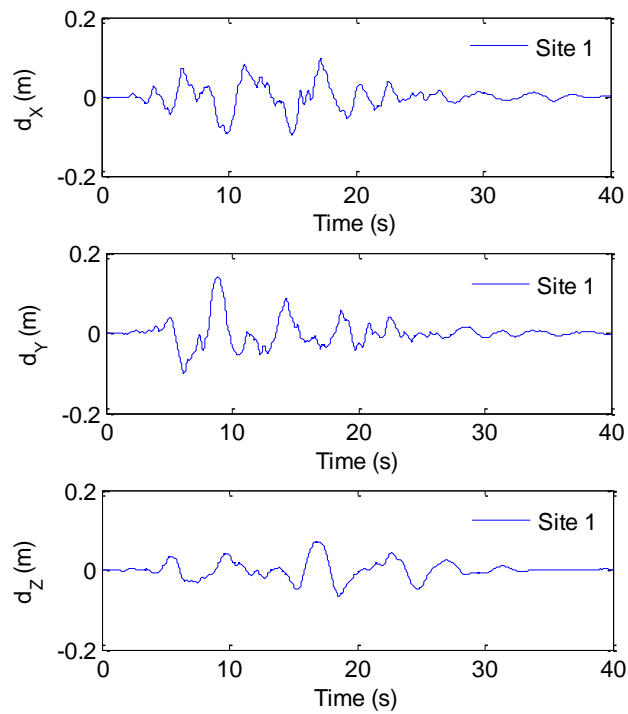
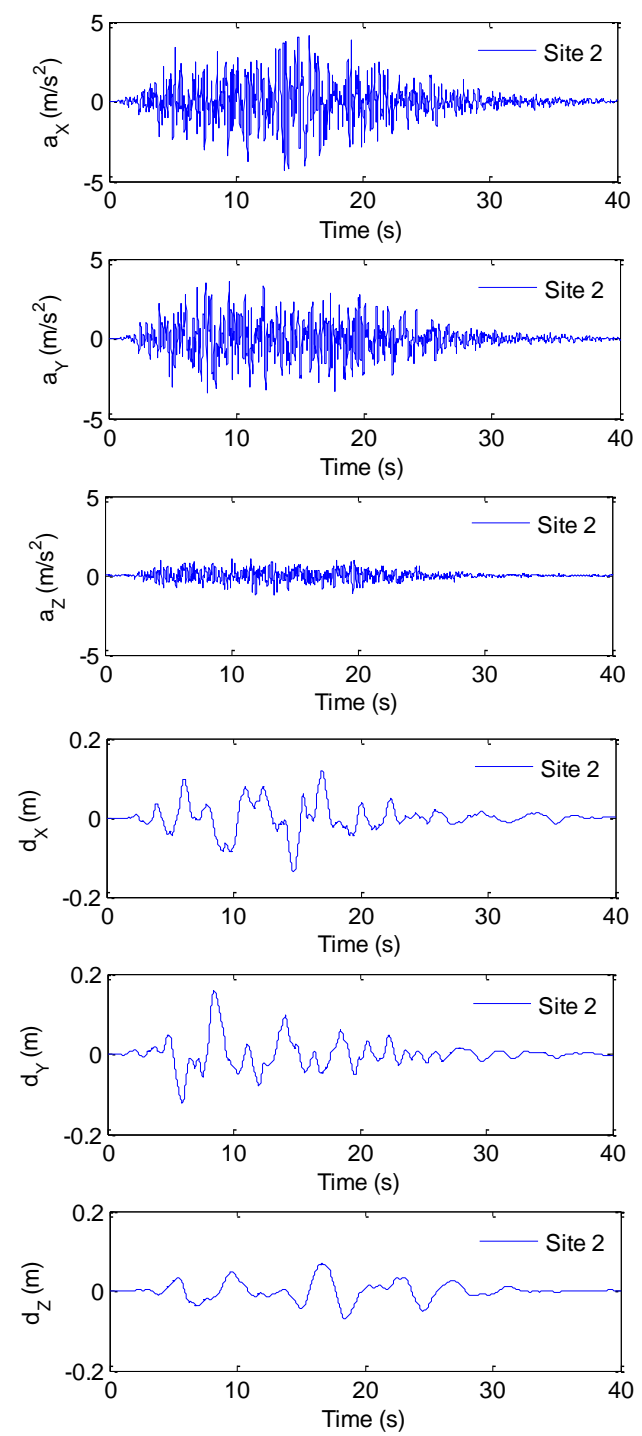

FIGURE 12 Generated three-dimensional spatially correlated ground motions on the surface of sites 1 and 2 (a) accelerations; (b) displacements.
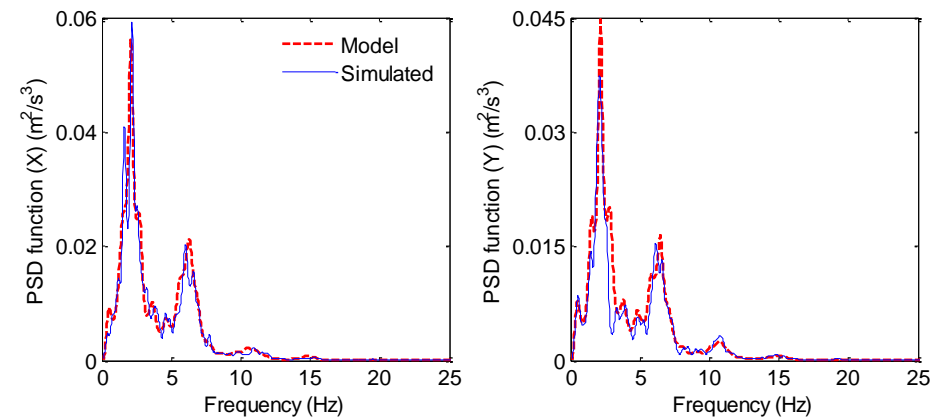
b

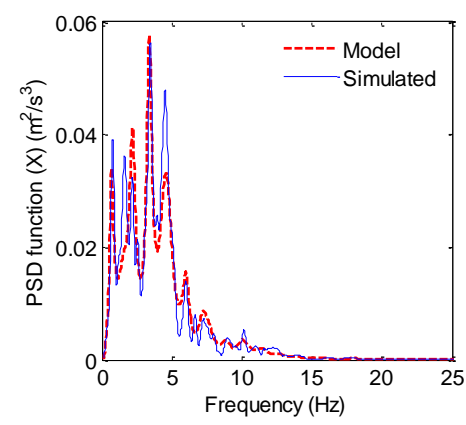

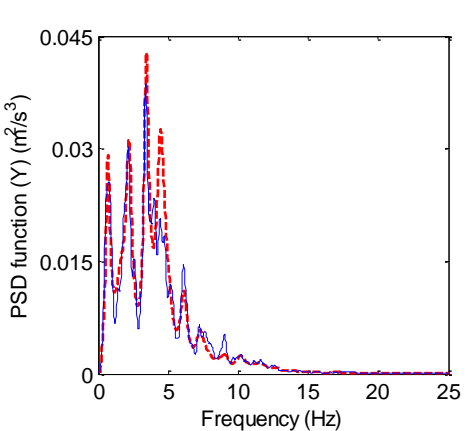

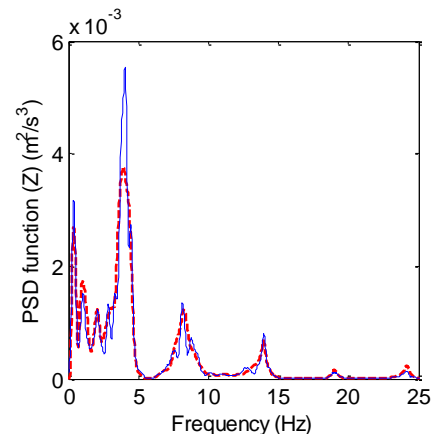

FIGURE 13 Comparison of PSD functions of the generated three-dimensional ground motions with the respective calculated PSD functions (a) site 1; (b) site 2

a

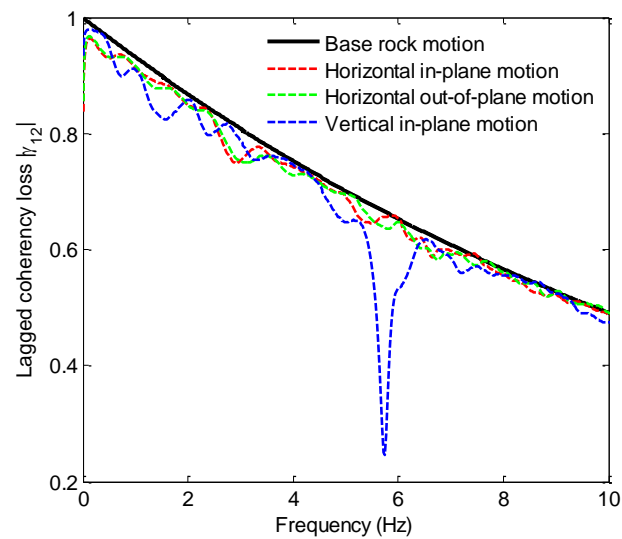

$\mathrm{b}$

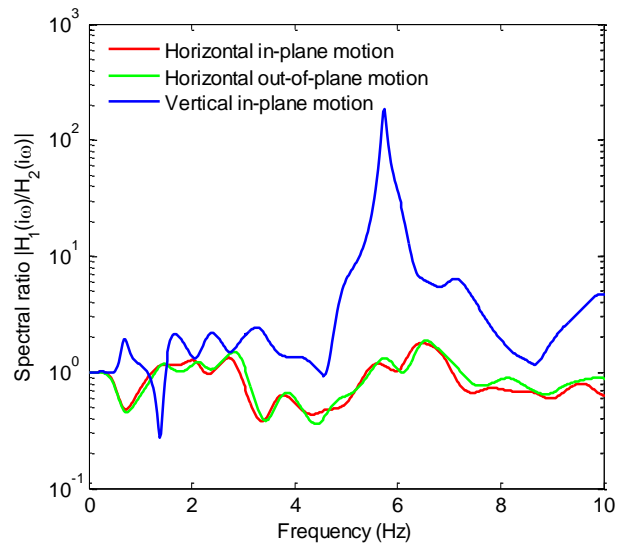

FIGURE 14 Influence of local site on the coherency loss between the three-dimensional ground motions on sites 1 and 2 (a) Comparison of lagged coherency loss; (b) Spectral ratio

Previous studies have revealed that local site condition not only influences the phase angle of coherency loss function between the ground motions on the site surface [Der Kiureghian, 1996], but also affects its modulus [Bi and Hao, 2011]. To calculate the converged mean lagged coherency loss functions between the ground motions on the base rock and site surface, a large number of simulations need to be carried out. In this study, convergence test is conducted and the results show that the mean lagged coherency loss functions at discrete frequencies are converged with 800 simulations. The mean values of 800 lagged coherency loss functions between the simulated spatially correlated ground motions on sites 1 and 2 and those between the base rock motions at sites 1' and 2' are plotted in Fig. 14(a). It can be observed that the lagged coherency loss between the spatially correlated motions on the site surface is reduced as compared to that between the base rock motions. Moreover, the peaks and troughs are related to the spectral ratio of the onshore and offshore sites as shown in Fig. 14(b). The spectral ratio can be calculated by $\left|H_{1}(i \omega) / H_{2}(i \omega)\right|$, where $H_{1}(i \omega)$ and $H_{2}(i \omega)$ are the transfer functions of the onshore and offshore sites, respectively. It can be concluded that the lagged coherency loss between spatial surface motions can be significantly influenced by the effects of soil saturation and seawater, since they directly affect the transfer functions of a local site as discussed in Sections 2 and 3. It can be seen that a severe reduction of lagged coherency loss between the vertical spatially correlated onshore and seafloor motions occurs near $5.73 \mathrm{~Hz}$, which corresponds to the P-wave resonant frequency of the overlying seawater layer. This is because the vertical transfer function of offshore site approaches 0 at the resonant frequency and leads to a maximum value of spectral ratio $\left(\left|H_{1}(i \omega) / H_{2}(i \omega)\right|=185\right)$, and the spatial ground motions on the site surface are least correlated at the frequencies 
where the power spectra of ground motions at the two sites are significantly different from each other.

\subsection{Comparison of simulated motions with actual seismic records}

The vertical-to-horizontal response spectral ratio (V/H RS ratio) is commonly employed to assess the difference between onshore and seafloor motions by researchers [Boore and Smith, 1999; Chen et al., 2015]. This is because it can eliminate the various factors on the seismic motions, such as earthquake magnitude, faulting mode, distance to epicenter and wave propagation path, except the effect of local geology of onshore and offshore sites [Boore and Smith, 1999]. In this section, a comparison of V/H RS ratios of the generated onshore and seafloor motions with those of the recorded motions is presented to examine the rationality of the simulated seafloor motions.

A pair of onshore and seafloor seismic motions recorded during one earthquake, namely the 6.5ML San Simeon Earthquake on 22 Dec, 2003, is employed in this paper. The map and relevant information of the epicenter, onshore and offshore stations are shown in Fig. 15. The elevations and S-wave velocities of the sites beneath the onshore and offshore stations can be respectively referenced from those given in the NGA-West2 site database [Ancheta et al., 2013] and the offshore site model for the coastal area of southern California defined by Boore and Smith [1999]. In this study, the elevations and S-wave velocities of the example onshore and offshore sites shown in Fig. 7 are set to be consistent with those suggested in the references for comparison purpose. Fig. 16 shows the acceleration time series of the onshore and seafloor recorded motions, which can be downloaded on the website of US National Center for Engineering Strong Motion Data (CESMD, http://strongmotioncenter.org).

In the calculation of $\mathrm{V} / \mathrm{H}$ RS ratios, the values of the two horizontal components are replaced by the geometric average of the individual values and the damping ratio is taken as $\xi=5 \%$. Convergence test is conducted and it is proved that the mean V/H RS ratios at discrete frequencies are converged with 800 simulations. The mean V/H RS ratios of 800 simulated onshore and seafloor motions are compared with those of the recorded motions in Fig.17. As shown, the $\mathrm{V} / \mathrm{H}$ spectral ratio of the simulated seafloor motion is much lower than that of the simulated onshore motion, especially at high frequency range; the same characteristic of the recorded onshore and seafloor motions can also be observed. These results are consistent with the previous study by Boore and Smith [1999], in which they concluded that the V/H spectral ratios of seafloor recordings are clearly much smaller than those of onshore recordings at relatively high frequencies more than $3 \mathrm{~Hz}$. Moreover, it can be observed that the $\mathrm{V} / \mathrm{H}$ spectral ratio of recorded seafloor motion achieves minimum value at $5.36 \mathrm{~Hz}$. This value is very close to the calculated P-wave resonant frequency $(5.73 \mathrm{~Hz})$ of the $73 \mathrm{~m}$ seawater layer, in view of the inevitable uncertainties in seawater depth and P-wave incident angles. It is also observed that the $\mathrm{V} / \mathrm{H}$ spectral ratios of the simulated onshore and seafloor motions are higher than those of respective recorded motions. This may be caused by the simple assumption of using constant $\mathrm{V} / \mathrm{H}$ ratio of $1 / 2$ for the base rock motions, which may overestimate the ground motion energy of the vertical base rock motion at higher frequencies. 


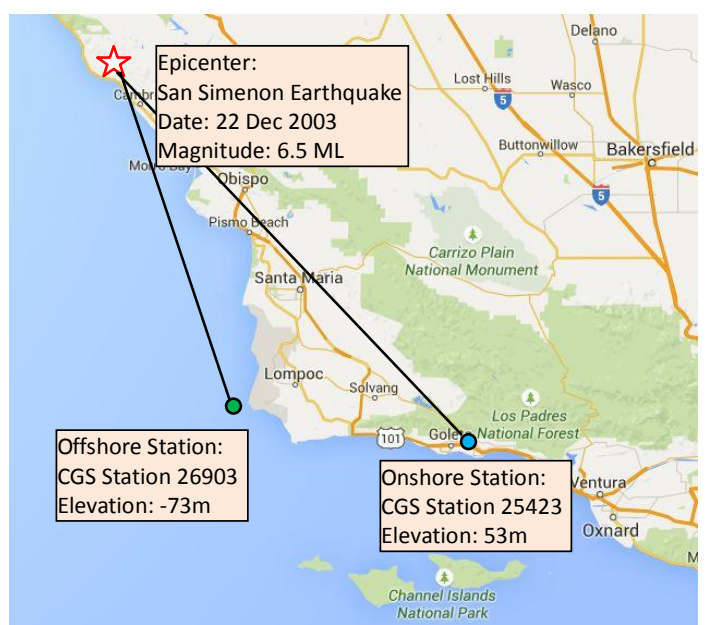

FIGURE 15 Sketch map of southern California with the locations of epicenter, onshore and offshore stations for the selected earthquake

a
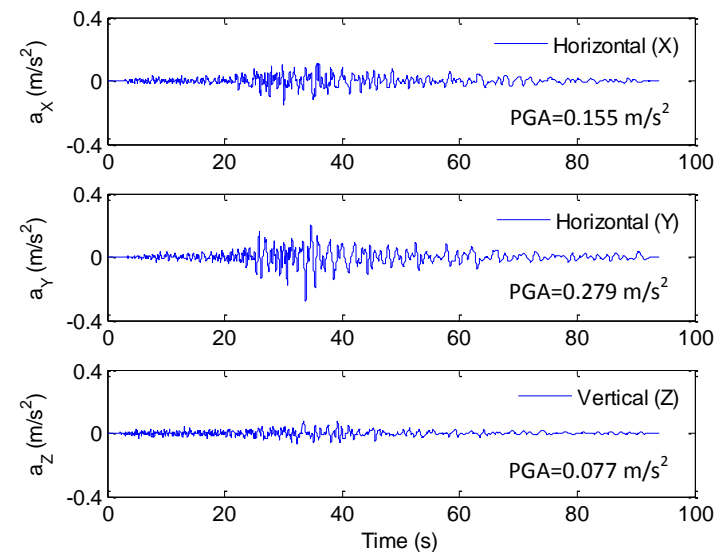

b
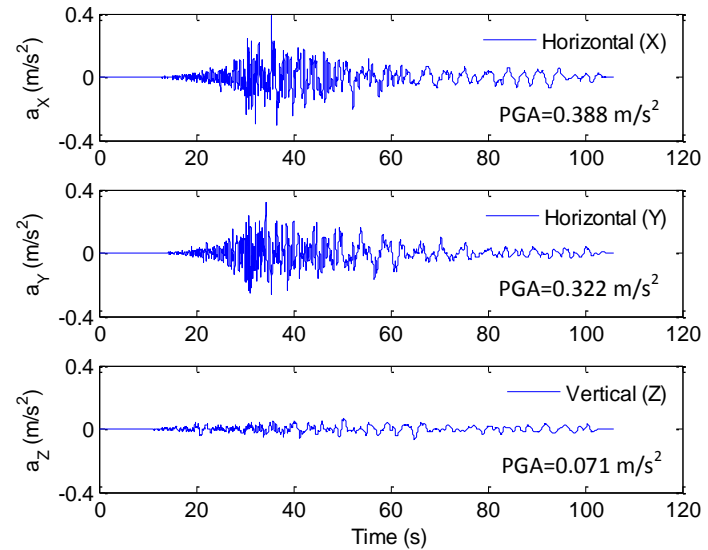

FIGURE 16 Three-dimensional accelerograms of selected earthquake recordings (a) onshore station; (b) offshore station

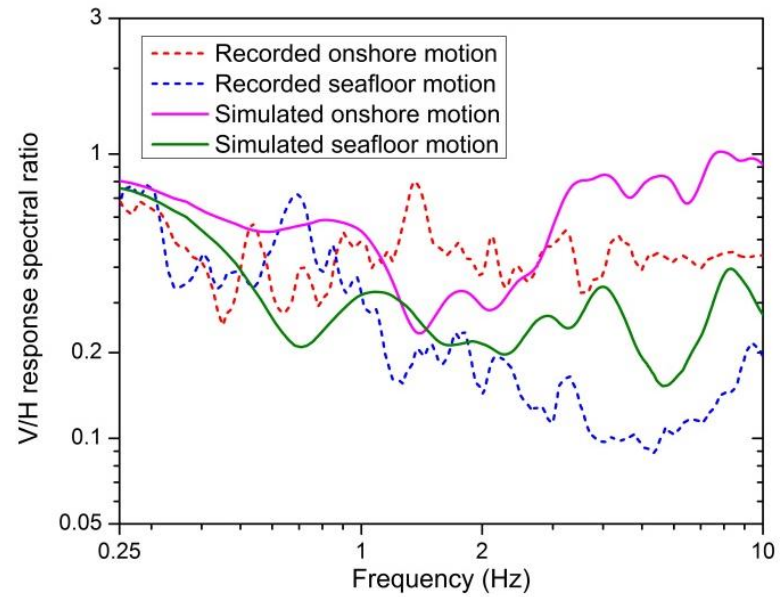

FIGURE 17 Comparison of V/H RS ratios of simulated motions with those of the recorded motions

It is worth noting that more recorded onshore and seafloor motions should be employed to verify the characteristics of simulated seafloor motions. However, it is very unfortunate that available seafloor recordings are very limited, especially for the onshore and seafloor motions recorded in the same earthquake event. Nonetheless, it can still be concluded that the simulated seafloor seismic motions can capture the most dominant feature of the seafloor 
recordings, namely the relatively low $\mathrm{V} / \mathrm{H}$ ratios at high frequency range (above $3 \mathrm{~Hz}$ ), caused by the significant suppression effect of vertical seafloor motion near the P-wave resonant frequencies of the seawater layer.

\section{Conclusions}

This paper proposes a simulation method of spatially correlated seismic motions at multiple onshore and offshore sites. The offshore site transfer functions are theoretically derived by considering the influences of seawater and water saturation of seafloor sediments. It is found that both of the two factors can significantly affect the site transfer functions of seafloor motions, especially in the vertical direction. The derived site transfer functions can be combined with the SRM to simulate spatially varying ground motions at multiple onshore and seafloor sites. The simulated spatial seismic motions match well with the respective target PSD functions individually and are compatible with the coherency loss model between each other. It is also demonstrated that the seawater layer could affect the coherency loss between the vertical ground motions at onshore and seafloor sites near the P-wave resonant frequencies of seawater. The comparison of $\mathrm{V} / \mathrm{H}$ RS ratios between simulated and recorded seismic motions reveals that characteristics of the simulated seafloor motions are in line with those of the recorded seafloor motions. Therefore, it is believed that the generated spatially correlated ground motions on the seafloor can be utilized as inputs in the seismic response analyses of large dimensional offshore engineering structures.

\section{Acknowledgments}

This research is supported by the National Basic Research Program of China (Grant No. 2011CB013605) and Australian Research Council Discovery Early Career Researcher Award (DECRA) DE150100195. The authors acknowledge the US National Center for Engineering Strong Motion Data (CESMD) for providing the onshore and seafloor records on their website. The first author also acknowledges the scholarship from the China Scholarship Council.

\section{References}

Ancheta, T. D., Darragh, R. B., Stewart, J. P., Seyhan, E., Silva, W. J., Chiou, B., Wooddell, K. E., Graves, R. W., Kottke, A. R., Boore, D. M., Kishida, T., and Donahue, J. L. [2013] "PEER NGA-West2 Database," PEER Report No. 2013/03, University of California, Berkeley, California.

Aoi, S., Kunugi, T., and Fujiwara, H. [2004] "Strong-motion seismograph network operated by NIED: K-net and Kik-net," Journal of Japan Association for Earthquake Engineering 4(3), 65-74.

Batchelor, G. K. [2000] An Introduction to Fluid Dynamics, Cambridge University Press, Cambridge.

Bi, K., Hao, H., and Chouw, N. [2010] "Required separation distance between decks and at abutments of a bridge crossing a canyon site to avoid seismic pounding," Earthquake Engineering and Structural Dynamics 39(3), 303-323.

Bi, K. and Hao, H. [2011] "Influence of irregular topography and random soil properties on coherency loss of spatial seismic ground motions," Earthquake Engineering and Structural Dynamics 40(9), 1045-1061.

$\mathrm{Bi}, \mathrm{K}$. and Hao, H. [2012] "Modelling and simulation of spatially varying earthquake ground motions at sites with varying conditions," Probabilistic engineering mechanics 29, 92-104.

Biot, M. A. [1956a] "Theory of propagation of elastic waves in a fluid-saturated porous solid. I. Low-frequency range," The Journal of the Acoustical Society of America 28(2), 168-178. 
Biot, M. A. [1956b] "Theory of propagation of elastic waves in a fluid-saturated porous solid. II. Higher frequency range," The Journal of the Acoustical Society of America 28(2), 179-191.

Boore, D. M. [1997] "Analysis of earthquake recordings obtained from the Seafloor Earthquake Measurement System (SEMS) instruments deployed off the coast of southern California," US Geological Survey, Open-File Report 97-733.

Boore, D. M. and Smith, C. E. [1999] "Analysis of earthquake recordings obtained from the Seafloor Earthquake Measurement System (SEMS) instruments deployed off the coast of southern California," Bulletin of the Seismological Society of America 89(1), 260-274.

Bozorgnia, Y. and Campbell, K. W. [2004] "The vertical-to-horizontal response spectral ratio and tentative procedures for developing simplified V/H and vertical design spectra," Journal of Earthquake Engineering 8(2), 175-207.

Chen, B., Wang, D., Li, H., Sun, Z., and Shi, Y. [2015] "Characteristics of Earthquake Ground Motion on the Seafloor," Journal of Earthquake Engineering 19, 874-904.

Clough, R.W. and Penzien, J. [1993] Dynamic of Structures, McGraw Hill, New York.

Crouse, C. B. and Quilter, J. [1991] "Seismic hazard analysis and development of design spectra for Maul A platform," Proc. of Pacific Conference on Earthquake Engineering, New Zealand, pp. 137-148.

Deodatis, G. [1996] "Non-stationary stochastic vector processes: seismic ground motion applications," Probabilistic Engineering Mechanics 11(3), 149-167.

Der, Kiureghian A. [1980] "Structural response to stationary excitation," Journal of Engineering Mechanics 106(6), 1195-1213.

Der Kiureghian, A. [1996] “A coherency model for spatially varying ground motions," Earthquake Engineering and Structural Dynamics 25(1), 99-111.

Diao, H., Hu, J., and Xie, L. [2014] "Effect of seawater on incident plane P and SV waves at ocean bottom and engineering characteristics of offshore ground motion records off the coast of southern California, USA," Earthquake Engineering and Engineering Vibration 13(2), 181-194.

Gao, Y., Wu, Y., Li, D., Liu, H., and Zhang, N. [2012] "An improved approximation for the spectral representation method in the simulation of spatially varying ground motions," Probabilistic engineering mechanics 29, 7-15.

Hao, H. [1989] "Effects of spatial variation of ground motions on large multiply-supported structures," UCB/EERC-89-06, University of California, Berkeley, California.

Hao, H. and Chouw, N. [2006] "Modeling of earthquake ground motion spatial variation on uneven sites with varying soil conditions," Proc. of the 9th International Symposium on Structural Engineering for Young Experts, Fuzhou, China, pp. 79-85.

Hao, H., Oliveira, C. S., and Penzien, J. [1989] "Multiple-station ground motion processing and simulation based on SMART-1 array data," Nuclear Engineering and Design 111(3), 293-310.

Hong, H. P. and Liu, T. J. [2014] "Assessment of coherency for bidirectional horizontal ground motions and its application for simulating records at multiple stations," Bulletin of the Seismological Society of America 104(5), 2491-2502.

Jensen, F. B., Kuperman, W. A., Porter, M. B., and Schmidt, H. [2011] Computational Ocean Acoustics, Springer, London.

Konakli, K., and Der Kiureghian, A. [2012] "Simulation of spatially varying ground motions including incoherence, wave-passage and differential site-response effects," Earthquake Engineering and Structural Dynamics 41(3), 495-513.

Li, C., Hao, H., Li, H., and Bi, K. [2015] "Theoretical modeling and numerical simulation of seismic motions at 
seafloor," Soil Dynamics and Earthquake Engineering 77, 220-225.

Lurton, X. [2002] An Introduction to Underwater Acoustics: Principles and Applications, Springer, New York.

Magda, W. [2000] "Wave-induced cyclic pore-pressure perturbation effects in hydrodynamic uplift force acting on submarine pipeline buried in seabed sediments," Coastal Engineering 39(2), 243-272.

Okada, Y., Kasahara, K., Hori, S., Obara, K., Sekiguchi, S., Fujiwara, H., and Yamamoto, A. [2004] "Recent progress of seismic observation networks in Japan-Hi-net, F-net, K-NET and KiK-net," Earth Planets Space 56, 15-28.

Rice, S. O. [1944] "Mathematical analysis of random noise," Bell System Technical Journal 23(3), 282-332.

RP 2A-WSD. [2000] Recommended practice for planning, designing and constructing fixed offshore platforms -working stress design, American Petroleum Institute, Houston.

Shinozuka, M. [1971] "Simulation of multivariate and multidimensional random processes," Journal of Acoustical Society America 49(1B), 357-368.

Shinozuka, M. [1987] "Stochastic fields and their digital simulation," Stochastic methods in structural dynamics. Springer, Netherlands.

Sleefe, G. E. [1990] "The long-term measurement of strong-motion earthquakes offshore southern California," Proc. of the 22nd Offshore Technology Conference, Houston.

Sobczky, K. [1991] Stochastic Wave Propagation, Kluwer Academic Publishers, Netherlands.

Tajimi, H. [1960] "A statistical method of determining the maximum response of a building structure during earthquakes," Proc. of 2nd World Conference on Earthquake Engineering, Tokyo, pp. 781-796.

Verruijt, A. [1969] Elastic storage of aquifers. In: Weist, R. J., editor. Flow Through Porous Media, Academic Press, New York.

Versteeg, H. K. and Malalasekera, W. [2007] An Introduction to Computational Fluid Dynamics: the Finite Volume Method, Pearson Education, England.

Wang, S. and Hao, H. [2002] "Effects of random variations of soil properties on site amplification of seismic ground motions," Soil Dynamics and Earthquake Engineering 22(7), 551-564.

Wolf, J. P. [1985] Dynamic Soil-Structure Interaction, Prentice Hall: Englewood Cliffs, NJ.

Wu, Y., Gao, Y., Li, D., Feng, T., and Mahfouz, A. H. [2014] "Comparison of the spectral representation method to simulate spatially variable ground motions," Journal of Earthquake Engineering 18(3), 458-475.

Yang, J. and Sato, T. [2000] "Interpretation of seismic vertical amplification observed at an array site," Bulletin of the Seismological Society of America 90(2), 275-285. 